\title{
Estruturação de Indicadores na Priorização de Concessão de Recursos para obras voltadas à Redução de Riscos de Desastres entre os Municípios do Estado do Paraná
}

\author{
Eduardo Gomes Pinheiro \\ Corpo de Bombeiros do Estado do Paraná - Curitiba - Paraná - Brasil \\ ORCID: http://orcid.org/0000-0001-5408-7883 \\ Larissa Maria da Silva Ferentz \\ Pontifícia Universidade Católica do Paraná (PUCPR) - Curitiba - Paraná - Brasil \\ ORCID: http://orcid.org/0000-0001-5804-0361 \\ Murilo Noli da Fonseca \\ Pontifícia Universidade Católica do Paraná (PUCPR) - Curitiba - Paraná - Brasil \\ ORCID: http://orcid.org/0000-0002-0718-3087
}

\begin{abstract}
Resumo
Segundo os dados da Coordenadoria Estadual de Defesa Civil do Paraná, os casos de desastre registrados no Estado diminuíram 37,6\% em relação ao ano anterior. No entanto, por mais que a quantidade de desastres tenha reduzido, o número de pessoas afetadas continua alto, assim como os municípios ainda enfrentam muita dificuldade para se recuperar dos eventos. Tendo em vista os atuais problemas enfrentados, o objetivo do presente artigo é apresentar um instrumento técnico-comparativo que auxilie os gestores na identificação dos municípios paranaenses prioritários para a concessão de investimentos com vistas à redução dos riscos de desastres. A metodologia se baseia na construção de um indicador formado pelas dimensões de Qualidade de Desastre e do Impacto e Comprometimento Econômico e Financeiro municipais. Como resultados, observa-se que com a aplicação do indicador, 239 municípios foram identificados como prioritários, sendo 12 deles em situação crítica, ou seja, deveriam ser os primeiros a receber recursos. Concluise que a utilização do presente indicador, para avaliação geral dos aspectos relacionados às consequências da ocorrência de desastres, pode se apresentar como um instrumento efetivo no auxílio aos gestores públicos para tomadas de decisão.
\end{abstract}

Palavras-chave: Indicador. Concessão de Recursos. Gestão de Riscos de Desastres. 


\title{
Structuring of Indicators in the Prioritization of Granting of Resources for works directed to the Reduction of Disaster Risk between the Municipalities of the State of Paraná
}

\begin{abstract}
According to data from the State Civil Defense Coordination of Paraná, the cases of disaster registered in the State decreased by $37.6 \%$ in relation to the previous year. However, as much as the number of disasters has reduced, the number of people affected remains high, as well as the municipalities still face great difficulty to recover from the events. In view of the current problems faced, the objective of this article is to present a technicalcomparative instrument that assists managers in the identification of priority Paraná municipalities for granting investments with a view to reducing disaster risks. The methodology is based on the construction of an indicator formed by the dimensions of Disaster Quality and Municipal Impact and Economic and Financial Commitment. As a result, it is observed that with the application of the indicator, 239 municipalities were identified as priorities, with 12 of them in critical condition, that is, they should be the first to receive resources. It is concluded that the use of this indicator, for general assessment of aspects related as a consequence of the occurrence of disasters, can present itself as an effective instrument in assisting public managers for decision making.
\end{abstract}

Keywords: Indicators. Granting of Resources. Risk Management.

\section{Estructurando los Indicadores en la Priorización de Recursos que otorgan Obras para Reducir los Riesgos de Desastres entre los Municipios del Estado de Paraná}

\section{Resumen}

Según datos de la Coordinación de Defensa Civil del Estado de Paraná, los casos de desastre registrados en el Estado disminuyeron en un 37,6\% en relación con el año anterior. Sin embargo, aunque la cantidad de desastres se ha reducido, la cantidad de personas afectadas sigue siendo alta, y los municipios aún enfrentan grandes dificultades para recuperarse de los eventos. En vista de los problemas actuales enfrentados, el objetivo de este artículo es presentar un instrumento técnico comparativo que ayude a los gerentes en la identificación de municipios prioritarios de Paraná para otorgar inversiones con miras a reducir los riesgos de desastres. La metodología se basa en la construcción de un indicador formado por las dimensiones de Calidad de Desastre e Impacto Municipal y Compromiso Económico y Financiero. Como resultado, se observa que con la aplicación del indicador, 239 municipios fueron identificados como prioridades, con 12 de ellos en estado crítico, es decir, deberían ser los primeros en recibir recursos. Concluye que el uso de este indicador para la evaluación general de los aspectos relacionados con la consecuencia de la ocurrencia de desastres, puede presentarse como una herramienta eficaz para ayudar a los gerentes en la toma de decisiones.

Palabras clave: Indicador. Concesión de recursos. Gestión del riesgo de desastres.

\section{Introdução}

O conceito de desastre se apresenta de forma muito variada na bibliografia. Mas, ao considerar o risco em um município, e a avaliação de todos os fatores envolvidos, ele pode ser entendido como sendo a interrupção no funcionamento de uma comunidade, ocasionando mortes, perdas ou impactos materiais, econômicos e ambientais, que excedem a capacidade da comunidade afetada em se recuperar mediante o uso dos seus próprios recursos (PINHEIRO, 2017). Entre 1998 e 2017, 
estima-se que os desastres deflagrados por fenômenos naturais vitimaram mais de 1,3 milhão de pessoas e deixaram mais de 4,4 bilhões de feridos, desabrigados, deslocados ou com a necessidade de assistência emergencial (CRED, 2018). Os países mais atingidos sofreram perdas econômicas no valor de S\$2.908 bilhões, dos quais US\$ 2.2.45 bilhões foram gerados por eventos relacionados ao clima (CRED, 2018).

No Brasil, a incidência da variedade dos tipos de desastres pelo território nacional é um fenômeno já consolidado em virtude das características específicas de cada região do país. Nos últimos anos, o que tem surpreendido os municípios, são as alterações dos eventos locais, com a ocorrência de eventos adversos pouco comuns ou inexistentes até então: em 2010, o Amazonas sofreu com as secas enquanto no ano anterior, 2009, o Estado teve que lidar com inundações; em 2004, Rio Grande do Sul e Santa Catarina foram atingidos pelo ciclone Catarina (FREITAS et al, 2014). Inserido nesse contexto, o Paraná apresenta várias ocorrências de eventos caracterizadas como desastres. Por exemplo, os incêndios ocorridos entre os meses de agosto e setembro de 1963; as inundações de 1983; o vazamento de óleo da Refinaria Getúlio Vargas, em 2000, em Araucária; do oleoduto OLAPA, em 2001, em Morretes; e do Navio Vicuña, em 2004, em Paranaguá (PINHEIRO, FERENTZ e FONSECA, 2019); incidência de tremores de terra, nos anos de 2016 e 2017.

Em 2018, o Estado registrou uma redução de 26,9\% de eventos adversos em relação a 2017 (PARANÁ, 2020). Mesmo com isso, o número de pessoas afetadas e de casos fatais continua alto. Dentre tais eventos, a ocorrência de vendavais, enxurradas e alagamentos continua sendo a mais frequente (PARANÁ, 2020). Entretanto, Ferentz, Fonseca e Pinheiro (2018) e Fonseca e Ferentz (2020) lembram que, apesar de os vendavais serem a tipologia de desastre mais recorrente, eles não estão inseridos no Plano de Contingência de Proteção e Defesa Civil, que é o instrumento municipal onde são registradas as áreas de atenção, abrigos, recursos e outros itens a serem considerados pelos órgãos envolvidos durante a resposta a desastres.

Como forma de minimizar os impactos decorrentes de tais eventos são necessários recursos financeiros para o desenvolvimento de ações de prevenção, mitigação e preparação (UNISDR, 2015). Na Europa, por exemplo, cada euro investido na redução de risco de desastres (RRD) pode representar uma economia significativa entre quatro e sete vezes no custo da resposta e recuperação dos desastres (IULIANO, 2014). No Estado do Paraná, o total de recursos previstos para as ações de 2020 até 2023 é de quase 26,2 milhões de Reais. As metas estão subdivididas entre iniciativas administrativas e das ações de proteção e defesa civil. A principal delas é a diminuição no tempo de resposta do atendimento aos municípios que notificarem a ocorrência de desastres. Neste caso, o objetivo é minimizar os impactos dos desastres nas comunidades, considerando as fases da gestão de riscos e desastres (prevenção, mitigação, preparação, resposta e recuperação) (PARANÁ, 2019).

No entanto, a falha na priorização de concessão de crédito por meio de financiamento voltado a obras e serviços destinados à RRD nos municípios acaba prejudicando o Estado como um todo. Em 2017, foi identificada a inexistência de priorização dos municípios a serem beneficiados com a concessão dos recursos. Os 
critérios utilizados foram considerados inadequados para o alcance dos objetivos da Política Nacional de Proteção e Defesa Civil, resultando na destinação de verbas para locais menos necessitados e uma aplicação ineficaz (TCU, 2017). A Confederação Nacional de Municípios (CNM) divulgou um alerta referente a falta de investimentos na prevenção de riscos e desastres, sendo que $98 \%$ dos recursos foram destinados a ações emergenciais de resposta e recuperação de áreas afetadas (CNM, 2017).

Por isso, faz-se necessário considerar a utilização de instrumentos que possam proporcionar a priorização ao conjunto formado pela Secretaria de Estado do Desenvolvimento Urbano (SEDU) e do Serviço Autônomo Paranacidade, com a Coordenadoria Estadual de Proteção e Defesa Civil do Paraná (CEPDEC/PR), no que se refere aos municípios paranaenses. A utilização de indicadores é a forma mais frequente para o emprego deste conceito, sendo um importante instrumento de auxílio para gestores públicos nos processos de tomada de decisão. Atualmente, a existência de indicadores locais viabiliza a priorização de ações e fundos, mas não permite a comparação entre municípios, dificultando a alocação dos recursos estaduais. Dessa forma, indicadores que avaliam a resiliência de desastres possibilitam a hierarquização e comparação de diferentes municípios, a fim de priorizar o capital necessário no Estado (GUNTHER, CICCOTI e RODRIGUES, 2017).

Portanto, o objetivo deste artigo é apresentar a estruturação de um indicador que possa ser utilizado pela CEDEC/PR e pela Secretaria de Desenvolvimento Urbano, para a identificação dos municípios paranaenses prioritários na concessão de recursos que visem a RRD. A estrutura do artigo foi organizada, primeiramente, com a apresentação dos conceitos e cenários atuais da concessão de recursos no país. Posteriormente, na metodologia, realiza-se a estruturação do indicador, com detalhamento das dimensões, variáveis e componentes. Por fim, a aplicação do instrumento de pesquisa no Paraná é apresentada, destacando os municípios prioritários pelas dimensões, e também, pela necessidade da concessão de recursos.

\section{Redução de risco de desastres}

A redução do risco de desastre passa pelo estabelecimento de políticas e práticas para minimizar a vulnerabilidade das comunidades. Para tanto, é imprescindível a adoção dos seus conceitos nas mais diversas áreas da gestão pública. A utilização de instrumentos para esse fim se faz necessária para a análise de todos os fatores que influenciam na ocorrência de desastres, conglomerando "a redução do grau de exposição às ameaças (perigos), a diminuição da vulnerabilidade das populações e suas propriedades, uma gestão prudente dos solos e do meio ambiente e o melhoramento da preparação diante dos eventos adversos" (EIRD, 2009, p. 27). O conjunto das ações que podem compreendem o antes, o durante e o após a ocorrência de desastres pode ser categorizado em cinco componentes: prevenção, mitigação e preparação (gestão de riscos) e a resposta e reconstrução - gestão de desastres (CEPED UFSC, 2012). Essas medidas podem ser classificadas em corretivas, onde as ações interferem nos riscos existentes, ou prospectivos, com base nos riscos prospectados a partir do processo conceptivo do 
planejamento, para que não sejam repetidos os mesmos erros do passado (FURTADO, 2012).

$\mathrm{Na}$ etapa de gestão de riscos, a prevenção se baseia na identificação de riscos e nas formas necessárias para reduzir ou impedir que ocorram. Juntamente com a capacitação dos atores que integram a gestão pública, estas avaliações devem ser consideradas nos processos de planejamento, gestão e decisões imediatas, permitindo a implementação de estratégias mais adaptáveis, como a comunicação de risco (LAMOND et al., 2019; FONSECA e GARCIAS, 2020). Com uma pesquisa estruturada, é possível realizar a classificação dos riscos, o custo estimado de possíveis intervenções e o desenvolvimento de um banco de dados com mapas de risco, vulnerabilidade e exposição (ONU, 2012). Porém, os bancos disponíveis não possuem um padrão ou um setor central de armazenamento. Cada um deles é elaborado e alimentado de forma individual, dificultando a integralidade, compartilhamento e integração das informações (ADEKOLA e LAMOND, 2018).

A mitigação é a busca pela diminuição dos efeitos negativos potenciais mensurados em termos de ameaças de degradação natural, tecnológica e ambiental através de medidas estruturais e não estruturais. Junto com a prevenção, ela depende de uma análise multidisciplinar da gestão de uso e ocupação do solo (VESTENA, 2007). A preparação é a etapa final da gestão de riscos. Ela visa adotar as medidas determinadas na prevenção e organizar estrategicamente a resposta durante o desastre, de modo que as ações sejam conhecidas por todos os agentes envolvidos durante o evento (PINHEIRO, 2017). Portanto, se não existe qualificação para lidar com os riscos, o resultado será a produção da vulnerabilidade, a elevação dos custos municipais pela necessidade de terceirização de serviços ou pelo aumento do prejuízo econômico que a falta de capacidade implicará (APDL, 2017)

$\mathrm{Na}$ gestão de desastres, a resposta se baseia nas direções, mobilizações e ações estratégicas que devem ser realizadas rapidamente, a fim de interceptar e reduzir os danos que os desastres podem causar, sobretudo em relação às perdas humanas. A recuperação consiste nas decisões e ações tomadas após o desastre, para melhorar e restaurar as condições da comunidade afetada. É uma oportunidade para novas medidas para reduzir o risco de desastres (PINHEIRO, 2017).

\section{Priorização de Concessão de Recursos}

A priorização de concessão de recursos que visam à RRD é um desafio que tem sido enfrentado pelos órgãos competentes. No Brasil, 957 municípios são monitorados pelo Centro Nacional de Monitoramento e Alerta de Desastres Naturais (Cemaden) em virtude de seu histórico de ocorrência de desastres decorrentes de inundações, enxurradas, alagamentos e/ou movimentos de massa. Atualmente, a gestão dos riscos e desastres é de responsabilidade do Sistema Nacional de Proteção e Defesa Civil (BRASIL, 2012), que é regido pela Política Nacional de Proteção e Defesa Civil complementada por um conjunto de Decretos Federais e normativas ministeriais. O Poder Executivo Federal deve apoiar aos municípios, priorizando o atendimento de toda a população "de acordo com a proporcionalidade do seu desastre e suas características socioeconômicas para 
resposta imediata e eficaz a fim de evitar ou aliviar o sofrimento humano e restabelecer a normalidade" (TCU, 2017).

O atual Ministério do Desenvolvimento Regional possui ações vinculadas aos Programas de Gestão de Riscos e Resposta a Desastres. Até 2019, o eixo 2240 visava auxiliar os gestores públicos na identificação das áreas de atenção nos municípios prioritários através do mapeamento de áreas de risco, implantar sistemas de alerta e de estruturas emergenciais, e definir diretrizes e ações para monitoramento das ocupações a promoção da prevenção de desastres, priorizando os municípios mais suscetíveis a deslizamentos, inundações, enxurradas e a seca. Esta promoção deve ocorrer por meio de instrumentos de planejamento urbano, a fim de monitorar as ocupações e de implantar intervenções estruturais e emergenciais (TCU, 2017).

Atualmente está em vigor o Plano Plurianual 2020-2023, no qual o eixo 2218 visa auxiliar os gestores na conservação, uso sustentável de recursos naturais e na melhoria da qualidade ambiental, levando em conta não só os benefícios do meio ambiente, como também, os custos envolvidos no processo. Dentre seus objetivos está o 1201, que busca investimentos para a compreensão da redução dos riscos, a preparação e a redução dos efeitos negativos dos desastres. Além disso, uma das metas do plano é ampliar a capacidade técnica dos municípios para a atuação da gestão de riscos e de desastres (TCU, 2020). São medidas necessárias para as ações de minimização dos riscos, uma vez que são pontos alvo de críticas nos últimos anos.

Entre 2004 e 2009, por exemplo, o Tribunal de Contas da União (TCU) divulgou os primeiros resultados quanto à evolução dos repasses na Gestão de Riscos e na Gestão de Desastres. Apenas em 2004, os investimentos tiveram um equilíbrio na concessão de recursos para as ações de prevenção e de resposta, apresentando nos anos seguintes uma disparidade na disponibilização de verbas. Um exemplo disso é o ano de 2009, que teve aproximadamente $R \$ 1,8$ bilhão investidos nas ações de resposta e apenas $R \$ 600$ milhões foram destinados à prevenção (RIBEIRO e BOREKI, 2010). Anos depois, o TCU divulgou uma nova nota, comprovando a falha da destinação de recursos do Programa Temático 2040, com destaque aos Estados que possuem a mesma média populacional em áreas de risco. Com aproximadamente 3 milhões de pessoas sujeitas a risco de desastres, os Estados do Ceará e Pará não foram contemplados pelo programa, assim como o Estado de Santa Catariana, que recebeu somente $\mathrm{R} \$ 1,5$ milhão. Por outro lado, 0 Estado da Bahia foi contemplado com mais de $\mathrm{R} \$ 120$ milhões, podendo-se perceber o contraste resultante dos critérios adotados e que, de acordo com o referido órgão, não condiz com os princípios da administração pública, como a eficiência e impessoalidade (TCU, 2017).

O relatório de auditoria da Fiscalização do Tribunal de Contas da União, divulgado recentemente, constatou que muitos recursos são destinados para projetos deficientes, pois não há análise prévia das propostas e dos custos. Isso se dá pela falha na estruturação e atuação dos órgãos municipais, pertencentes ao Sistema Nacional de Proteção e Defesa Civil. Esta falta de preparação dos gestores resulta em ações falhas de prevenção, por exemplo. Dentre os instrumentos analisados, quanto sua existência ou não no município, estão os Planos Diretores Municipais ou os de Redução de Riscos que contemplem medidas de prevenção de desastres; mapas de uso e ocupação do solo com indicação das áreas inundáveis; 
leis específicas para a prevenção de deslizamentos, enxurradas ou inundações; e cartas geotécnicas com permissividade de áreas urbanas. Destaca-se que a média do Brasil, para municípios que não apresentaram nenhum dos instrumentos citados, foi quase $60 \%$ (TCU, 2020).

Outro ponto destacado, foi quanto ao direcionamento de recursos realizado para entes específicos da Federação, sendo considerado como ineficiência da administração pública e, até mesmo, como um ato imoral. A destinação com interesses pessoais deve ser analisada e julgada em processo administrativo, visto que o poder público deve atuar de maneira imparcial. Além disso, também foi indicado que a distribuição de recursos continua sem critérios técnicos para a seleção de projetos, resultando em destinações para áreas menos necessitadas (TCU, 2020).

A partir dessa conjuntura, percebe-se que a realidade se sintetiza pela inexistência de recursos suficientes para o saneamento financeiro das ações de gestão de risco de desastres, associado à escassez de preparação técnica e critérios objetivos comparativos determinantes das prioridades. Deste modo, a distribuição equânime depende do desenvolvimento desses critérios para apoiar os gestores em todos os níveis, especialmente no federal e estadual. Adotando-se o Estado do Paraná como um recorte espacial no país, considerando haver recursos estaduais disponíveis para o investimento em ações e obras nos municípios, estruturou-se um indicador a fim de oferecer um parâmetro técnico-comparativo entre os municípios afetados por desastres, em um período temporal pré-definido.

\section{Metodologia: Estruturação do Indicador}

A criação de um instrumento de medição sintético capaz de apontar os danos, prejuízos e impactos sobre a economia e a capacidade de investimento dos municípios comumente comprometida com a ocorrência desses eventos, se faz necessária devido a inexistência de critérios adequados para a priorização da concessão de recursos atualmente. A estruturação do presente indicador se dá por meio de critérios relacionados à recorrência de desastres num recorte temporal determinado, sendo suas variáveis agrupadas em duas dimensões específicas.

A fonte de dados utilizada foi o Sistema Informatizado de Defesa Civil (SISDC), que possui dados redundantes dos formulários de informação do desastre e outros mais aprofundados que os constantes no sistema federal S2iD. Foram adotados dados populacionais oriundos do perfil dos municípios paranaenses disponibilizados pelo Instituto Paranaense de Desenvolvimento Econômico e Social (IPARDES), combinados com as somatórias fornecidas pelas seleções realizadas diretamente no SISDC. O propósito do indicador é poder ranquear os municípios por prioridade a partir de critérios que proporcionem a necessária equidade, uma vez que suas diferenças são muito sensíveis em várias dimensões.

O índice que se propõe a construir será resultante de um indicador sintético. Conforme a OECD (2008), o desenvolvimento de indicadores sintéticos se depara com a necessidade do enfrentamento de certo grau justificável de ceticismo. Isso se deve à falta de transparência de alguns indicadores existentes, dados e metodologias. Em que pese comumente tais indicadores serem utilizados para 
sintetizar indicadores sociais, nesta pesquisa a síntese será de dimensões compostas por variáveis selecionadas, as quais relacionam dados que, posteriormente, se estabelecem gradações mensuráveis. Entretanto, para que se possa compreender a estrutura do indicador e, consequentemente, afastar ao máximo o ceticismo, será dada total transparência aos critérios adotados para a estruturação e às fontes de dados que serão utilizados para a aplicação. Antes, no entanto, de se apresentarem as duas dimensões componentes do indicador, convém apresentar seu modelo de estruturação, conforme demonstra a Figura 1:

Figura 1 - Composição do Indicador-Base de Priorização de Municípios.

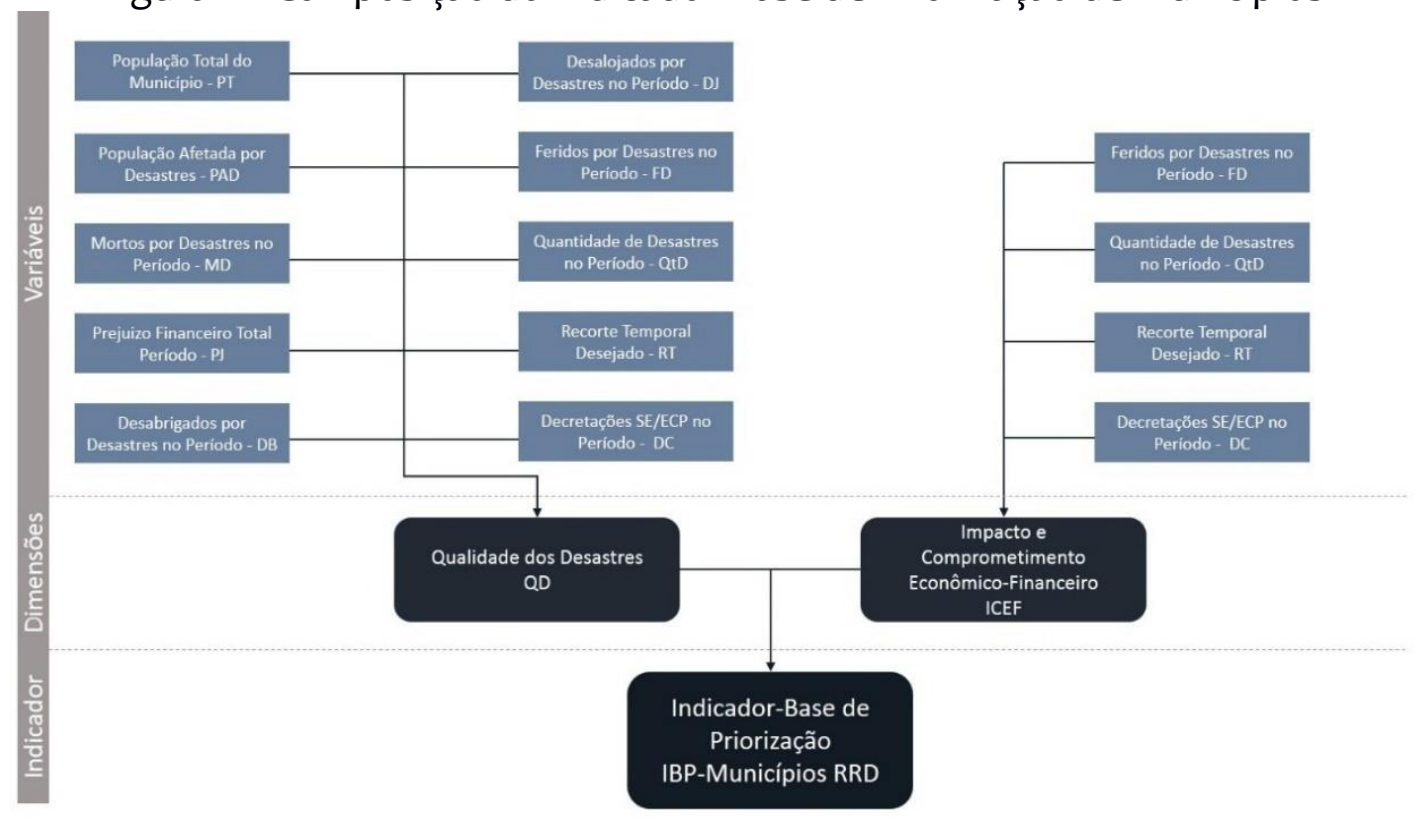

Fonte: os autores.

A primeira dimensão é chamada Qualidade dos Desastres e diz respeito às características dos eventos na forma como costumam se manifestar nos municípios, a partir do recorte temporal e dos dados disponíveis. A segunda dimensão é o Impacto Econômico-Financeiro, a qual é capaz de determinar a comparação e o consequente comprometimento do município a partir da análise do montante de prejuízos registrados por conta dos desastres versus seus indicadores dessa natureza. A seguir será abordada cada variável que a compõe e suas características.

\subsection{Qualidade dos desastres}

Para determinar a Qualidade dos Desastres nos municípios paranaenses, foram selecionadas dez variáveis que se referem à quantidade de desastres, período de apuração dessa quantidade adotada, a população total do município, a somatória dos prejuízos financeiros, a quantidade de episódios de decretação de Situação de Emergência (SE) ou de Estado de Calamidade Pública (ECP) no período, além do número de pessoas afetadas, mortas, feridas, desabrigadas e desalojadas. Tomou-se o cuidado de verificar previamente a existência de dados capazes de alimentarem a relação das variáveis necessária, justamente para garantir que o modelo seja exequível em qualquer dos municípios. A descrição de cada uma dessas 
variáveis e os critérios mensuráveis para sua adoção podem ser observados nas tabelas 1 e 2.

Tabela 1. Descrição da Dimensão Qualidade dos Desastres

\begin{tabular}{|c|c|c|}
\hline Sigla & Indicador & Descrição \\
\hline PT & $\begin{array}{l}\text { População total do } \\
\text { município }\end{array}$ & $\begin{array}{l}\text { Quantidade de habitantes registrada e disponibilizada pelo IBGE, } \\
\text { para o ano de encerramento da análise do recorte temporal. A } \\
\text { unidade de medida é quantidade de pessoas (habitantes). }\end{array}$ \\
\hline RT & Recorte temporal & $\begin{array}{l}\text { Período de anos selecionado no que se refere à quantidade } \\
\text { compreendida pelo intervalo. A unidade é expressa em anos. }\end{array}$ \\
\hline QtD & $\begin{array}{l}\text { Quantidade de } \\
\text { desastres }\end{array}$ & $\begin{array}{l}\text { Total de ocorrências de desastres registrado no período } \\
\text { compreendido no recorte temporal. Tem como unidade de } \\
\text { medida a quantidade de desastres. }\end{array}$ \\
\hline PAD & $\begin{array}{l}\text { População afetada por } \\
\text { desastres no período }\end{array}$ & $\begin{array}{l}\text { Total de pessoas afetadas direta ou indiretamente obtendo-se } \\
\text { pela somatória do apontado nos relatórios referentes às } \\
\text { ocorrências de desastre compreendidas no recorte temporal } \\
\text { escolhido. Também, incluem-se nesse número, os feridos, mortos, } \\
\text { desalojados, desabrigados e deslocados. A unidade utilizada para } \\
\text { esta variável é quantidade de pessoas. }\end{array}$ \\
\hline MD & $\begin{array}{l}\text { Mortos decorrentes dos } \\
\text { desastres no período }\end{array}$ & $\begin{array}{l}\text { Somatória do número de casos fatais registrados como } \\
\text { mortes/óbito nos formulários de registros de desastre } \\
\text { correspondente ao contido no recorte temporal selecionado. }\end{array}$ \\
\hline DB & $\begin{array}{l}\text { Desabrigados por } \\
\text { conta dos desastres no } \\
\text { período }\end{array}$ & $\begin{array}{l}\text { Somatória dos números apontados nos relatórios das ocorrências } \\
\text { de desastres registradas durante o período referente ao recorte } \\
\text { temporal no que se refere àquelas pessoas que, devido à } \\
\text { ocorrência ou na iminência da expansão dos efeitos decorrentes } \\
\text { de um determinado desastre principal ou dos secundários } \\
\text { deflagrados pelo mesmo evento adverso, tenham precisado } \\
\text { deixar suas casas necessitando, no entanto, de um abrigo público } \\
\text { provisório ou permanente para permanecer até que possam } \\
\text { retornar para suas casas ou outro local definido pelo poder } \\
\text { público local. A unidade é a quantidade de pessoas. }\end{array}$ \\
\hline DJ & $\begin{array}{c}\text { Desalojados por conta } \\
\text { dos desastres no período }\end{array}$ & $\begin{array}{l}\text { Somatória das quantidades de pessoas que, devido à ocorrência } \\
\text { de ocorrência ou na iminência da expansão dos efeitos } \\
\text { decorrentes de um determinado desastre principal ou dos } \\
\text { secundários deflagrados pelo mesmo evento adverso, tenham } \\
\text { precisado deixar suas casas necessitando, no entanto, recorrer à } \\
\text { casa de parentes, amigos ou conhecidos para que permaneçam lá } \\
\text { até que haja o retorno à normalidade na região onde } \\
\text { normalmente habitam. A unidade é a quantidade de pessoas. }\end{array}$ \\
\hline FD & $\begin{array}{l}\text { Feridos por conta dos } \\
\text { desastres no período }\end{array}$ & $\begin{array}{l}\text { Resultado da apuração, nos relatórios de informação sobre os } \\
\text { desastres ocorridos dentro do recorte temporal pré-estabelecido, } \\
\text { das pessoas apontadas como aquelas que, por algum motivo } \\
\text { relacionado às consequências do evento desastroso, tenham se } \\
\text { ferido, independentemente de terem sido encaminhadas a algum } \\
\text { estabelecimento de saúde ou não. A unidade utilizada para esta } \\
\text { variável é quantidade de pessoas. }\end{array}$ \\
\hline PJ & $\begin{array}{l}\text { Prejuízo resultante dos } \\
\text { eventos registrados no } \\
\text { período }\end{array}$ & $\begin{array}{l}\text { Somatória da apuração dos danos e prejuízos convertidos em } \\
\text { moeda do impacto resultante dos eventos desastrosos inseridos } \\
\text { no recorte temporal, em Reais ( } \mathrm{R} \$ \text { ). }\end{array}$ \\
\hline DC & Quantidade de & Quantidade de ocorrências de desastres as quais, devido à \\
\hline
\end{tabular}




\begin{tabular}{c|c|l}
\hline & $\begin{array}{c}\text { decretações de SE/ECP } \\
\text { no período }\end{array}$ & $\begin{array}{l}\text { vultuosidade da somatória dos danos e prejuízos, bem como de } \\
\text { vítimas fatais, atingiu os índices prescritos pela legislação federal } \\
\text { vigente resultando na decretação, pelo Chefe do Executivo } \\
\text { municipal, de Situação de Emergência ou de Estado de Calamidade } \\
\end{array}$ \\
$\begin{array}{ll}\text { Pública. Esta variável compreende a somatória das decretações } \\
\text { compreendidas no período escolhido como recorte temporal, } \\
\text { sendo que o número que as representa é único e se refere a } \\
\text { ambos os tipos de decretação, sua unidade, portanto, é número } \\
\text { de decretações. }\end{array}$ \\
\hline
\end{tabular}

Fonte: os autores.

A partir da determinação das variáveis, é possível relacioná-las pelo processo de estruturação dessa dimensão do indicador, para que, resultando da comparação de dados existentes e disponíveis sobre os municípios, possa haver critérios proporcionais e justos de comparação e classificação de prioridades.

O subindicador, ou a dimensão Qualidade do Desastre é definido como a caracterização dos componentes percebidos como consequência dos eventos desastrosos no município. Desta forma, foram escolhidos seis subcomponentes a partir das variáveis disponíveis. Estes passam a ser designados por letras, quais sejam, A, B, C, D, E e F, sendo compostos por cálculos específicos a partir das variáveis apresentadas anteriormente. Cada um possui atribuição de peso, escala e uma convenção específica, as quais podem ser observadas na tabela 2.

Tabela 2. Resumo dos Subcomponentes Qualidade dos Desastres

\begin{tabular}{|c|c|c|c|c|}
\hline \multicolumn{5}{|c|}{ Convenções } \\
\hline Grupo & Fórmula & Peso & Valor & Convenção \\
\hline A & $\mathrm{A}=\mathrm{Q} \mathrm{tD} / \mathrm{RT}$ & 2 & $\begin{array}{c}0 \\
1 \text { a } 2 \\
3 \text { a } 5 \\
\text { maior } 5\end{array}$ & $\begin{array}{c}0 \\
0,10 \\
0,15 \\
0,20\end{array}$ \\
\hline B & $\mathrm{B}=(\mathrm{PAD} * 100) / \mathrm{PT}$ & 1 & $\begin{array}{c}0 \\
1 \text { até 10\% } \\
\text { 10,01 a 30\% } \\
\text { 30,01 a } 50 \% \\
\text { maior que } 50 \%\end{array}$ & $\begin{array}{c}0 \\
0,03 \\
0,05 \\
0,08 \\
0,10\end{array}$ \\
\hline C & $C=P J / P T$ & 1 & $\begin{array}{c}0 \\
0,01 \text { a 5,00 } \\
5,01 \text { a } 10,00 \\
\text { maior que } 10\end{array}$ & $\begin{array}{c}0 \\
0,03 \\
0,07 \\
0,10\end{array}$ \\
\hline D & $D=(D C * 100) / Q t D$ & 2 & $\begin{array}{c}0 \\
1 \text { a } 5 \\
5 \text { a } 10 \\
\text { maior que } 10\end{array}$ & $\begin{array}{c}0 \\
0,12 \\
0,17 \\
0,20\end{array}$ \\
\hline E & $\mathrm{E}=[(\mathrm{PAD} / \mathrm{QtD}) * 100] / \mathrm{PT}$ & 2 & $\begin{array}{c}0 \\
0,1 \text { a } 10 \% \\
\text { 10,01 a } 30 \% \\
\text { maior que } 30 \%\end{array}$ & $\begin{array}{c}0 \\
0,12 \\
0,17 \\
0,20\end{array}$ \\
\hline $\mathrm{F}$ & $\mathrm{F}=[(\Sigma \mathrm{MD} ; \mathrm{DB} ; \mathrm{DJ} ; \mathrm{FD}) * 100] / \mathrm{PAD}$ & 2 & $\begin{array}{c}0 \\
0,01 \text { a } 10 \% \\
\text { 10,01 a } 20 \% \\
\text { maior que } 20 \%\end{array}$ & $\begin{array}{c}0 \\
0,12 \\
0,17 \\
0,20\end{array}$ \\
\hline
\end{tabular}


Fonte. os autores.

A partir dos subníveis apresentados e da sua caracterização, a composição da fórmula para determinação do subindicador referente à dimensão denominada como Qualidade do Desastre é dada pela seguinte equação:

$$
D Q D=\Sigma(A ; B ; C ; D ; E ; F)
$$

Onde:

DQD - Dimensão Qualidade do Desastre.

$\Sigma$ - Somatório.

A - Razão entre a quantidade de desastres e o recorte temporal escolhido.

B - Porcentagem da população total afetada por desastres no período.

C - Prejuízo Total resultante dos desastres per capita no município.

D - Razão estabelecida entre a quantidade de desastres e os que resultaram em decretação de Situação de emergência ou Estado de Calamidade Pública, independentemente de homologação ou reconhecimento.

E - Percentual da população afetada a cada desastre no período.

F - Percentual de afetados diretamente pelos desastres no período

selecionado dentre a população total.

O índice encontrado, que enfatiza o impacto humano à normalidade da vida humana naquele município, estará compreendido entre os valores de 0 a 1 e é crescente para a definição do maior grau de gravidade dos desastres no período, de acordo com as variáveis que determinam a qualidade dos eventos.

\subsection{Dimensão do impacto e comprometimento econômico-financeiro}

Cada desastre possui, obrigatoriamente, um impacto a ser medido, o qual atinge de forma significativa a capacidade financeira dos municípios. Como se propõe a metodologia em questão, em comparar municípios afetados por desastres num recorte temporal específico e definido, faz-se necessário avaliar outra dimensão de eventos ocorridos: o seu Impacto e Comprometimento Econômico $e$ Financeiro. Para este índice, serão adotadas variáveis escolhidas a partir da disponibilidade do banco de dados da CEDEC/PR: o Produto Interno Bruto (PIB), a Receita Corrente Líquida, o prejuízo total resultante dos eventos registrados no período e a população total do município. Reitera-se que tais dados são automaticamente buscados, quando do preenchimento eletrônico da documentação após o acometimento de desastre num município, da base de dados do IPARDES.

Para o desenvolvimento das fórmulas específicas que definem as variáveis que se constituem base para se chegar à dimensão que apura o impacto econômicofinanceiro, os conceitos vigentes são apresentados na tabela 3. Tomando como base as definições apresentadas, inicia-se o processo de estruturação relacionando as variáveis, para que, assim como na Qualidade do Desastre, possa haver critérios proporcionais, transparentes e justos de comparação e classificação de prioridades. 
Tabela 3. Descrição da Dimensão Impacto e Comprometimento Econômico-

Financeiro

\begin{tabular}{|c|c|c|}
\hline Sigla & Indicador & Descrição \\
\hline PIB & $\begin{array}{c}\text { Produto Interno } \\
\text { Bruto }\end{array}$ & $\begin{array}{l}\text { Soma, em moeda, de todos os bens e serviços finais produzidos } \\
\text { num determinado município no último ano da análise, de acordo } \\
\text { com os dados disponibilizados no SISDC da Coordenadoria Estadual } \\
\text { de Proteção e Defesa Civil do Paraná. }\end{array}$ \\
\hline $\mathrm{RCL}$ & $\begin{array}{l}\text { Receita Corrente } \\
\text { Líquida }\end{array}$ & $\begin{array}{l}\text { Somatório das receitas tributárias, de contribuições, patrimoniais, } \\
\text { agropecuárias, industriais, de serviços, transferências correntes } \\
\text { outras receitas também correntes, deduzidas as eventuais } \\
\text { transferências e as despesas previstas em lei. Para fins de cálculo é } \\
\text { adotada a RCL do último ano do intervalo medido de tempo, dado } \\
\text { disponibilizado no SISDC da Coordenadoria Estadual de Proteção e } \\
\text { Defesa Civil do Paraná. }\end{array}$ \\
\hline PJ & $\begin{array}{l}\text { Prejuízo total } \\
\text { resultante dos } \\
\text { eventos registrados } \\
\text { no período }\end{array}$ & $\begin{array}{l}\text { Somatória da apuração dos danos e prejuízos convertidos em } \\
\text { moeda do impacto resultante dos eventos desastrosos inseridos no } \\
\text { recorte temporal, em Reais (R\$). }\end{array}$ \\
\hline PT & $\begin{array}{l}\text { População total do } \\
\text { município }\end{array}$ & $\begin{array}{l}\text { Quantidade de habitantes registrada e disponibilizada pelo IBGE, } \\
\text { para o ano de encerramento da análise do recorte temporal. A } \\
\text { unidade utilizada é quantidade de pessoas (habitantes). }\end{array}$ \\
\hline
\end{tabular}

Fonte. os autores.

Para a elaboração do presente subindicador, que define a segunda das duas dimensões necessárias para a construção do indicador, foram determinados três componentes a partir das variáveis disponíveis. Esses componentes passam a ser designados pelas letras $\mathrm{G}, \mathrm{H}$ e J. As características referentes ao peso, fórmula, escala e convenção, podem ser observadas na Tabela 4.

Tabela 4. Resumo dos Subcomponentes Impacto e Comprometimento Econômico-Financeiro

\begin{tabular}{|c|c|c|c|c|}
\hline \multicolumn{5}{|c|}{ Convenções } \\
\hline Grupo & Fórmula & Peso & Valor & Convenção \\
\hline G & $\mathrm{G}=\left(\mathrm{H}^{*} 100\right) /(\mathrm{PIB} / \mathrm{PT})$ & 3 & $\begin{array}{c}0 \\
0,01 \text { a } 15 \% \\
\text { 15,01 a } 25 \% \\
\text { maior que } 25 \%\end{array}$ & $\begin{array}{c}0 \\
0,10 \\
0,20 \\
0,30\end{array}$ \\
\hline$J *$ & $\mathrm{~J}=\mathrm{PJ} / \mathrm{PT}$ & 3 & $\begin{array}{c}0 \\
0,01 \text { a } 15,00 \\
15,01 \text { a } 30,00\end{array}$ & $\begin{array}{c}0 \\
0,08 \\
0,15 \\
\end{array}$ \\
\hline
\end{tabular}




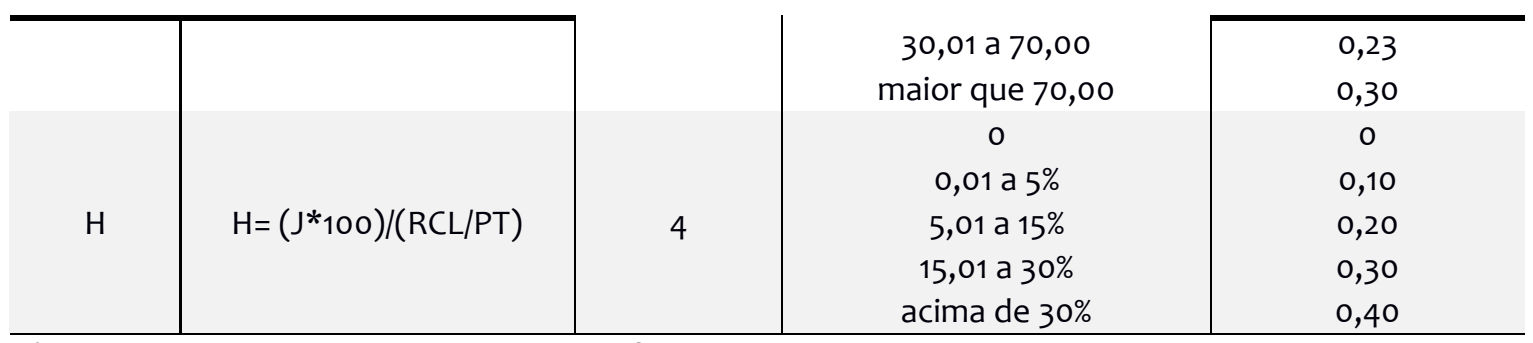

* O subcomponente J possui a mesma fórmula do subcomponente $\mathrm{C}$ apresentado anteriormente (Tabela 2), sendo, porém, suas características distintas quanto ao peso e quanto aos valores convencionados.

Fonte. os autores.

Destarte, a fórmula a seguir determina o cálculo da dimensão referente ao Impacto e Comprometimento Econômico-Financeiro, a partir dos três componentes apresentados e da sua caracterização:

\section{DICEF = $\Sigma(G ; J ; H)$}

Onde:

DICEF - Dimensão do Impacto e Comprometimento Econômico-Financeiro.

$\Sigma$ - Somatório.

A - Razão entre a quantidade de desastres e o recorte temporal escolhido.

B - Porcentagem da população total afetada por desastres no período.

C - Prejuízo Total resultante dos desastres per capita no município.

O valor encontrado estará compreendido na mesma escala do subindicador anterior, entre os valores de 0 a 1 , sendo crescente para a definição do maior grau de gravidade de impacto econômico e financeiro dos desastres no período, de acordo com as subdimensões que aferem esses eventos.

4.3 Indicador base

Apresentadas as duas dimensões e suas variáveis, resta relacioná-las por meio da equação final que define o indicador responsável pelo ranqueamento dos municípios para a determinação da prioridade do aporte de recursos voltados à RRD.

Sua composição é dada pela integração das dimensões exibidas antes, sendo sua fórmula estruturada da seguinte maneira:

\section{Indicador-Base $=[\Sigma \text { DICEF; DQD }]^{*} 0,5$ \\ $\operatorname{DICEF}=\Sigma(\mathrm{G} ; \mathrm{J} ; \mathrm{H})$}

Onde:

Indicador-Base - Parâmetro para determinar o grau de necessidade de investimento em RRD no município. 
$\Sigma$ - Somatório.

A - Razão entre a quantidade de desastres e o recorte temporal escolhido.

B - Porcentagem da população total afetada por desastres no período.

O valor determinado pelo indicador estará compreendido entre o (zero) e 1 (um) sendo crescente para a definição do maior grau de necessidade de se receber investimentos. A prioridade, para facilitar a composição de grupos distintos, pode ser escalonada em seis categorias: muito baixa (0), baixa $(0,1-0,25)$, razoável $(0,26$ $-0,50)$, alta $(0,51-0,75)$ e muito alta $(0,76-1,00)$.

\section{Resultados do Estudo Piloto}

A fim de se avaliar a efetividade do presente modelo de indicadores, foi realizado o estudo piloto dentro de um período amostral compreendido entre 20092019. Sua aplicação se deu a partir dos dados disponíveis junto à base do Sistema Informatizado de Defesa Civil (SISDC), do Instituto Brasileiro de Geografia e Estatística (IBGE) e do Instituto Paranaense de Desenvolvimento Econômico e Social (IPARDES). Foram obtidas as informações de $n^{\circ}$ de desastres, pessoas afetadas, situação de emergência, valor do prejuízo ocasionado pelos desastres, dentre outros.

No recorte temporal definido (RT), o Estado do Paraná registrou um número total de ocorrências de desastres (QD) de 5.473, uma média de 497 por ano (mínimo de 403 em 2016 e máximo de 652 em 2015) (GRÁFICO 1). Tais eventos atingiram, em média, 211 municípios (mínimo de 168 em 2010 e máximo de 257 em 2012). O município com a maior quantidade de eventos foi o de Curitiba (174), seguido de Maringá (121) e Araucária (102). Em relação ao número de pessoas atingidas (PAD), o Estado apresentou um total de 10.163 .827 pessoas, sendo Cascavel (930.580), Maringá (672.392) e Foz do Iguaçu (615.271) aquelas com o maior número de vítimas.

Gráfico 1. Ocorrências e Municípios Afetados (2009-2019)

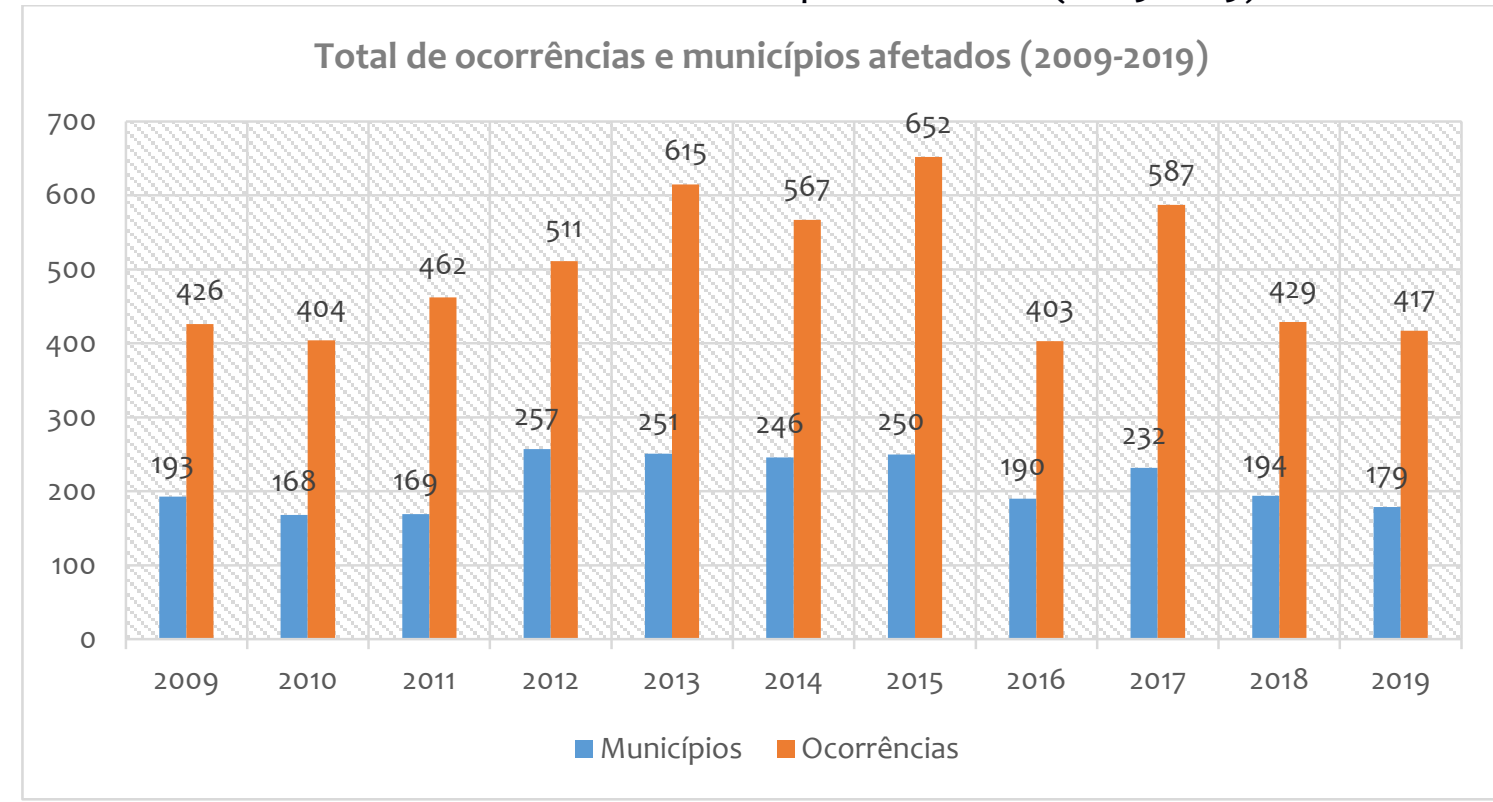


Fonte. CEDEC/PR, 2020.

Dentre o número de desastres, os municípios que tiveram os maiores casos de decretos de Situação de Emergência (DC) foram Prudentópolis (15), Querência do Norte (12), Bom Jesus do Sul (11) e Santo Antônio do Sudoeste (11). A partir da caracterização de ocorrências, obteve-se o valor total de prejuízos ( $P J)$ no Estado no recorte temporal determinado. Considerando os desastres ocorridos neste período, o prejuízo total foi de $\mathrm{R} \$ \mathbf{7} 887.255 \cdot 386,23$. Os municípios que tiveram os maiores prejuízos financeiros foram os de Pitanga ( $R \$ 183.720 .733,82$ ), Prudentópolis ( $R \$$ 176.362.839,05) e Terra Roxa ( $\mathrm{R} \$ 160.993 .210,00)$.

5.1 Priorização de concessão de recursos para obras voltadas à RRD no Paraná

Com a obtenção das informações, foi possível realizar a aplicação do indicador proposto. Na primeira dimensão, Qualidade do Desastre (DQD), a maior parcela dos municípios foi classificada como alvo de "muito alta prioridade" (267), seguido por alta (79), razoável (34), baixa (1) e muito baixa (18) (FIGURA 2).

Figura 2. Dimensão Qualidade do Desastre no Estado do Paraná (2009-2019)

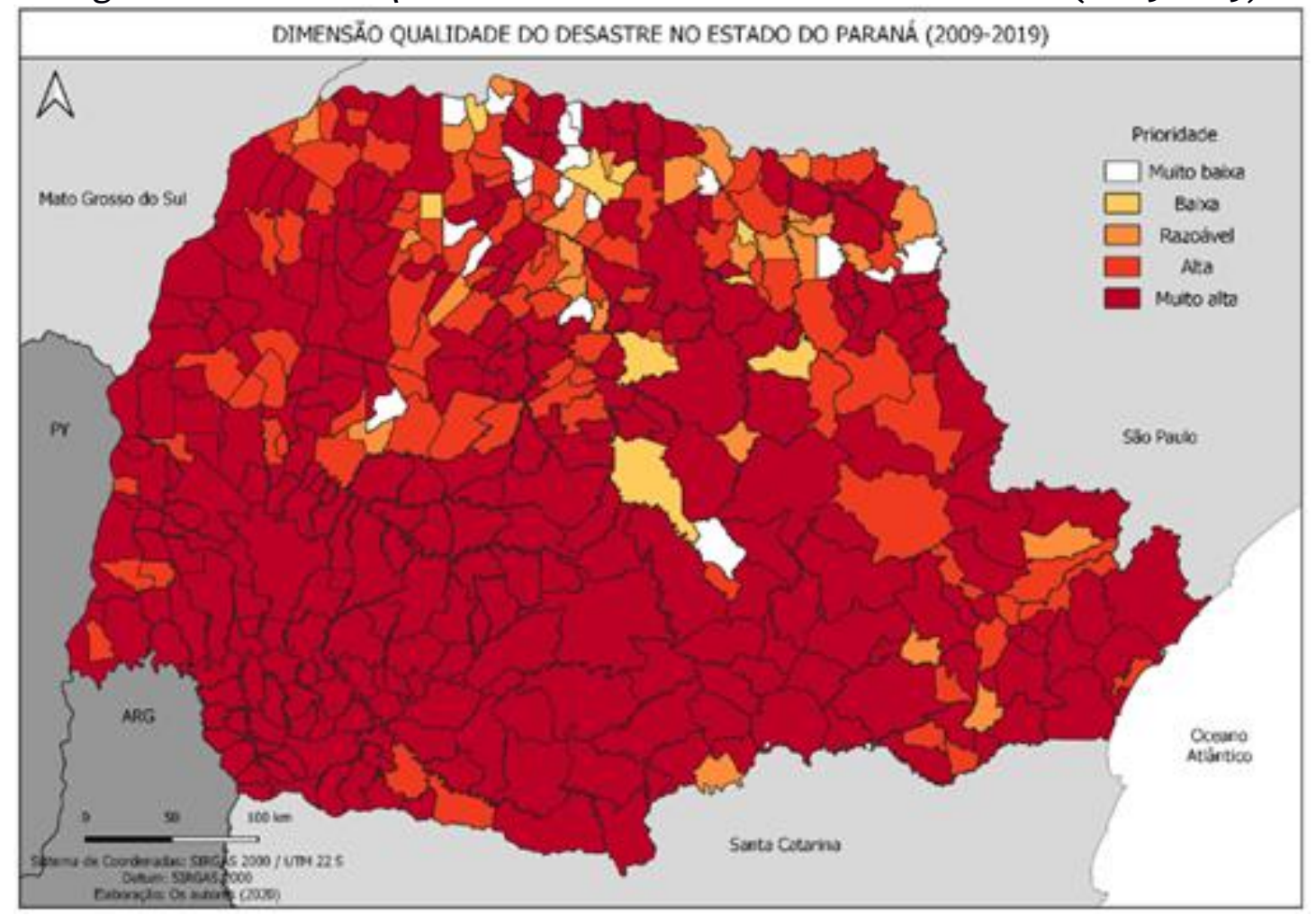

Fonte. os autores.

Já na segunda dimensão, "Impacto e Comprometimento EconômicoFinanceiro" (DICEF), a maior parcela dos municípios foi classificada como sendo objeto de "muito alta prioridade" (336), muito baixa (40), regular (14), alta (7) e baixa (0) (FIGURA 3). Devido à ausência de dados de Receita Corrente Líquida, os municípios de Lindoeste e Inajá não foram considerados na análise. 
Figura 3. Dimensão Impacto e Comprometimento Econômico e Financeiro no Paraná (2009-2019)

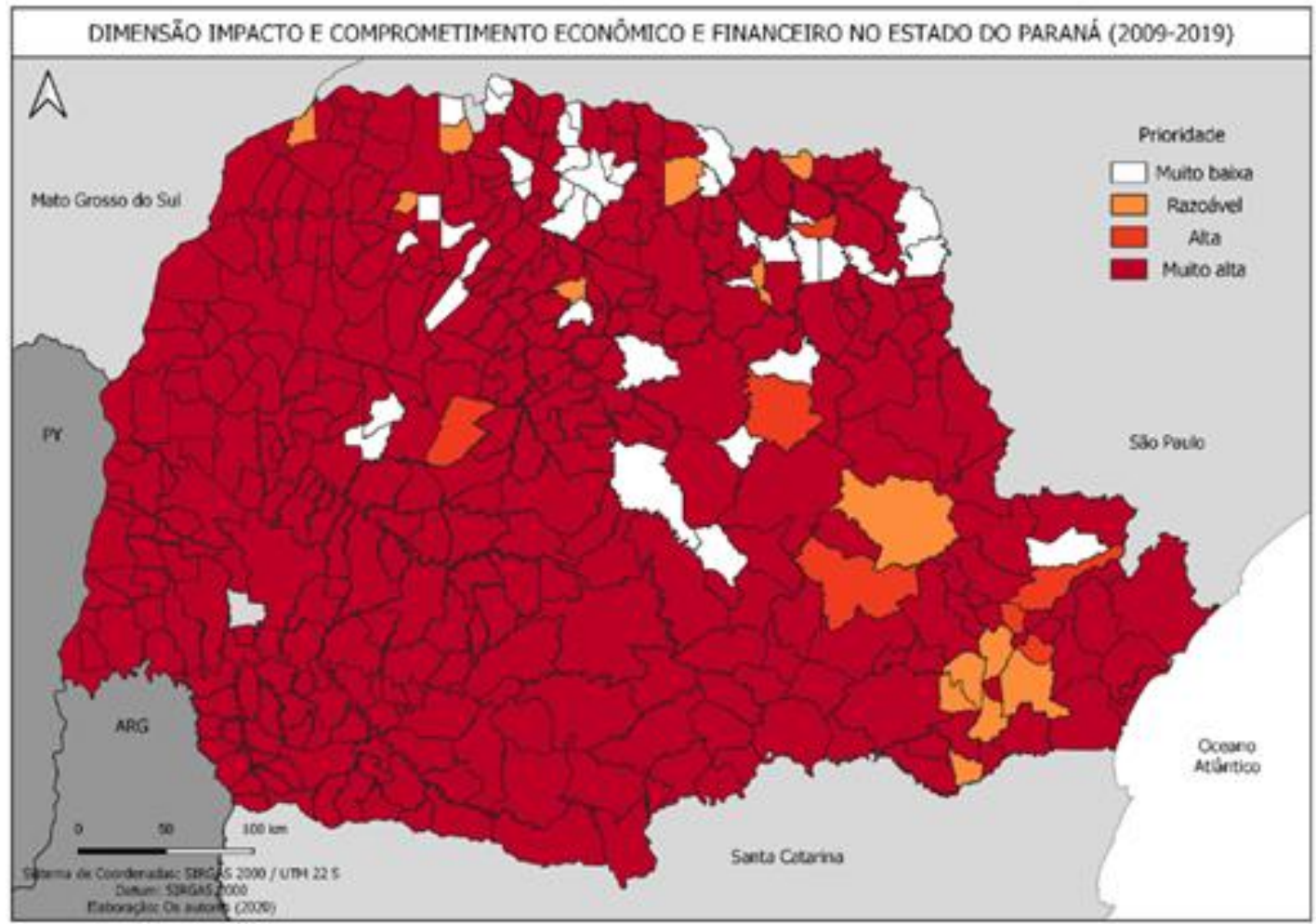

Fonte. os autores.

Quando as dimensões são integradas, o que se apresentou como primeira prioridade foi Santo Antônio do Sudoeste, com valor de 0,985 (FIGURA 4). O epigrafado município resultou em uma média para a dimensão de Qualidade do Desastre (DQD) de 0,97. Para a dimensão de Impacto e Comprometimento Econômico-Financeiro (DICEF), a média obtida foi de 1,00. Com uma população total de 20.166 pessoas, o município, localizado no Sudoeste do Paraná, é o mais crítico.

No recorte temporal adotado foram registrados 33 desastres, dos quais 11 resultaram em declaração de Situação de Emergência ou Estado de Calamidade Pública. Os eventos deflagradores de desastres mais recorrentes são Vendaval (13), Enxurradas (11), Granizo (5), Estiagem (3) e Inundações (1). Como resultado, houve 47.605 pessoas afetadas, nenhuma morte, 723 pessoas desabrigadas, 29 feridos e 4.389 desalojados. 
Figura 4. Priorização de concessão de recursos para obras voltadas à RRD no Paraná (2009-2019)

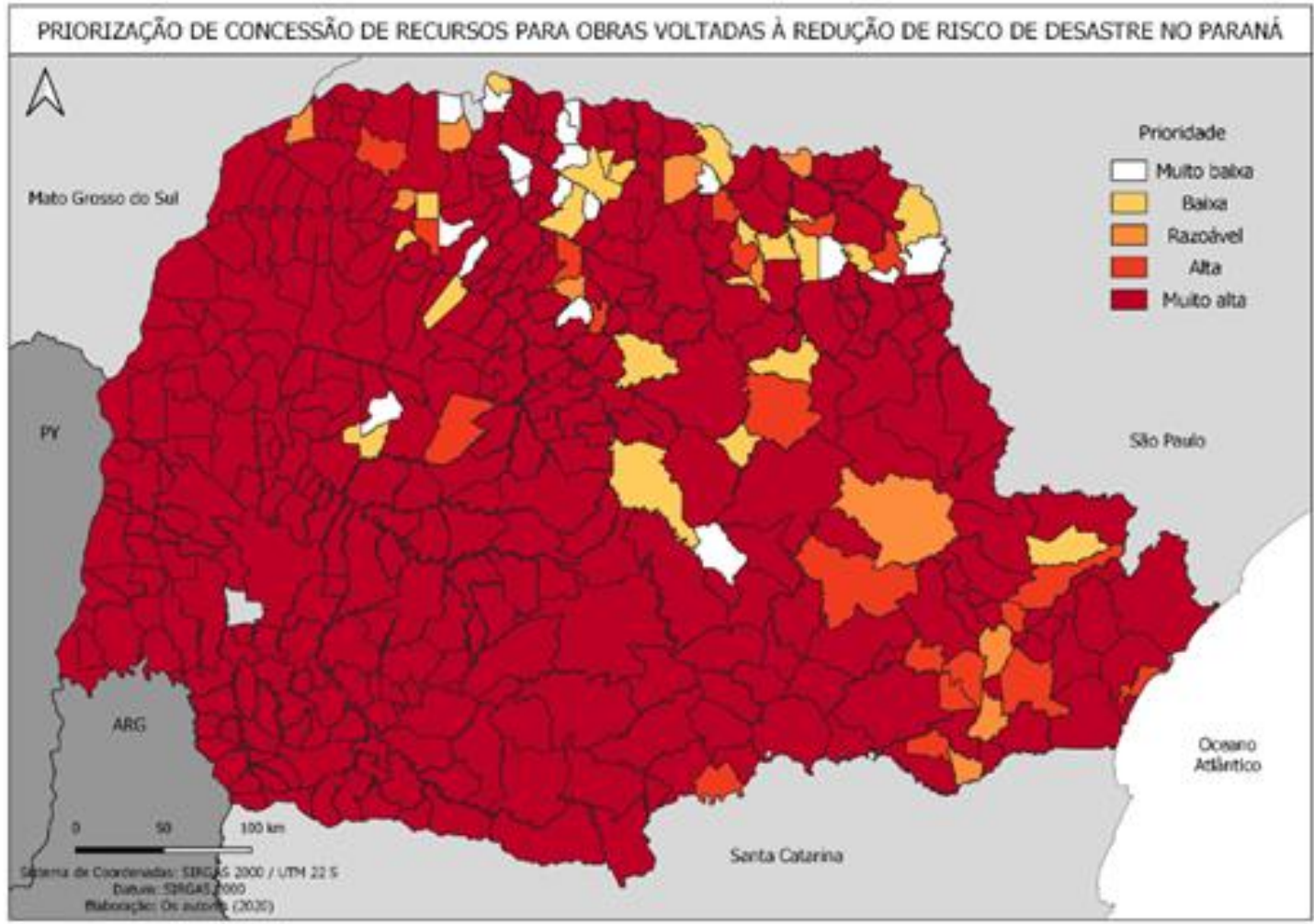

Fonte. os autores.

O segundo município mais crítico é Querência do Norte, com um valor de 0,97. O município apresenta índice de Qualidade do Desastre de 0,94. Para a dimensão de Impacto e Comprometimento Econômico-Financeiro, atingiu-se valor máximo: 1,00.

Após ele, nove municípios apresentam um índice final de 0,96, sendo estes Capitão Leônidas Marques, Francisco Beltrão, General Carneiro, Morretes, Pinhais, Rebouças, Santa Lucia, Tibagi e União da Vitória. Destaca-se também que 26 municípios obtiveram o total do índice como Zero, sendo sua classificação considerada como sem prioridade.

\subsection{Concessão de recursos para a RRD}

Os resultados obtidos indicam que o número de municípios considerados prioritários para o recebimento de recursos é próximo ao apresentado pelo antigo Ministério das Cidades (239 versus 268). Por mais que se tenha essa proximidade, 170 municípios foram considerados críticos pelo Ministério, um valor bem acima do 
encontrado pelos critérios do Indicador-Base, com 12 municípios. Considerando a transferência de recursos pelo governo federal em ações de resposta e reconstrução - Plano Detalhado de Resposta (PDR) e Plano de Trabalho de Reconstrução (PTR) - foram consideradas todas as informações disponíveis dentro do período em estudo, sendo estas dos anos de 2013 a 2019. Dentro deste período, 19 concessões foram disponibilizadas para municípios paranaenses, totalizando $\mathrm{R} \$$ 5.099.201,14 em repasses. Ao analisar os municípios que receberam as verbas, todos aqueles pertencente ao grupo de municípios críticos pelo indicador foram contemplados. Nenhum município qualificado como Baixa Prioridade recebeu verbas.

Tais recursos são de caracterização obrigatória, enquanto os para a prevenção de desastres é realizada de forma voluntária. Entre 2006 e 2014, verificase um leve aumento da porcentagem do PIB nacional investido na gestão de riscos e desastres. Passa-se de 0,009\% em 2006 para 0,04\% em 2011 (após o desastre ocorrido na região serrana do Rio de Janeiro) e, posteriormente, uma diminuição para 0,011\% no ano de 2014 (MARCHEZINI et al., 2017). Este cenário transparece a realidade das informações quanto aos dados ligados às obras de prevenção. Dos dados divulgados no Portal da Transparência (2020), verifica-se o contraste dos investimentos realizados em 2019 no Brasil e no Paraná. O total de recursos disponibilizados para obras de Proteção e Defesa Civil no país foi de 644,6 milhões, sendo 7,2\% (46,4 milhões) destinados ao Paraná. Quanto à destinação para obras preventivas, dos 226,5 milhões aportados em todo o país pelo Governo Federal, o Paraná recebeu 667 mil (0,30\%). Na Itália, por exemplo, estima-se que são necessários $€ 44$ bilhões para reduzir o risco hidrogeológico em bacias hidrográficas no país, porém, houve o investimento de um terço desse montante no período compreendido entre 1999-2023 (PALEARI, 2018).

A aptidão de um conjunto de fatores estratégicos ajuda a determinar o acesso ou não a recursos pelos municípios, também. Trata-se de uma situação já verificada por vários autores. Kellett, Caravani e Pichon (2014), por exemplo, afirmam que os principais desafios relacionados à política de concessão de recursos para a RRD são referentes à (1) transparência e prestação de contas, sobretudo de sua eficácia (Phaup e Kirschner, 2010); (2) alta concentração de recursos no governo federal; (3) desarticulação institucional; (4) capacidade local para investimento; e (5) ausência de informação sobre procedimentos administrativos a fim de acessar o financiamento.

Não há estudos análogos para a definição de critérios como os que foram desenvolvidos neste trabalho, que tenham sido localizados na pesquisa. Por parecer óbvio a sua necessidade num país com as dimensões que o Brasil possui, acredita-se na possibilidade de extensão da sua aplicação ao restante do país, como sugestão para trabalhos futuros ou, ainda, haver a sua integração com outros indicadores municipais voltados à aferição da capacidade de preparação para desastres.

\section{Considerações Finais}

A aplicação eficiente de recursos financeiros para a redução do risco de desastre é essencial para garantir a prevenção, auxiliar na mitigação dos danos 
sofridos pelas comunidades e, principalmente, salvar vidas tornando os municípios, lugares mais seguros para viver. Uma vez que o orçamento de gestão de riscos e desastres de diferentes níveis de governo é considerado um investimento público, a eficácia e gestão do investimento devem ser verificadas. Por isso, o desenvolvimento desse indicador teve por objetivo subsidiar os responsáveis da CEDEC/PR e da Secretaria do Desenvolvimento Urbano (SEDU/Paranacidade) nas decisões referentes ao aporte de recursos voltados ao financiamento para investimento em obras voltadas à redução de riscos de desastres nos municípios paranaenses.

Com a construção do Indicador-base foi possível analisar os municípios prioritários a partir de critérios mais claros para a avaliação do impacto recorrente de desastres, atendendo às recomendações exaradas pelo Tribunal de Contas da União e auxiliando na obtenção de resultados mais efetivos, a fim de contribuir para uma melhor tomada de decisão. Os resultados obtidos não traduzem o nível de preparação ou de ativação das coordenadorias municipais de proteção e defesa civil, apenas significam a comparação entre dados dos desastres que acometeram tais municípios na unidade do tempo escolhido.

Salienta-se que a menção feita ao Tribunal de Contas da União nesta análise, deve-se à predominância das transferências de recursos financeiros ocorrer a partir do Governo Federal, portanto, fiscalizadas por aquele órgão de controle, donde surgem as recomendações que foram enfatizadas para parametrizar o estudo.

Como desafio futuro, é importante que o presente indicador continue sendo aplicado anualmente, com vistas a analisar ser os municípios adotados atualmente, são de fato os que mais precisam de recursos naquele momento. Essas informações poderão servir de base para os gestores, tanto para a fiscalização do Estado, quanto para comprovação da necessidade de investimentos.

Desta forma, conclui-se que a adoção do presente indicador pode ser uma importante ferramenta nos processos decisórios para os gestores públicos na definição dos municípios prioritários para a recepção de recursos, independentemente das variadas fontes existentes, nos diferentes níveis e instituições de financiamento nacionais e internacionais.

\section{REFERÊNCIAS}

ADEKOLA, O.; LAMOND, J. A media framing analysis of urban flooding in Nigeria: Current narratives and implication for policy. Regional Environmental Change, v. 18, p. 1145-1159, 2018

APDL - Administração dos Portos do Douro, Leixões e Viana do Castelo. Plano de Prevenção e Mitigação de Riscos de Gestão, incluindo os Riscos de Corrupção e Infrações Conexas. Portugal: APDL, 2017.

BRASIL. Decreto $\mathbf{n}^{\circ} \mathbf{7 . 2 5 7}$ de 4 de agosto de 2010. Regulamenta a Medida Provisória $\mathrm{n}^{\circ} 494$ de 2 de julho de 2010, para dispor sobre o Sistema Nacional de Defesa Civil SINDEC. Brasília: 4 de agosto de 2010. 
BRASIL. Lei n 12.608 de 10 de abril de 2012. Institui a Política Nacional de Proteção e Defesa Civil - PNPDEC. Brasília: 10 de abril de 2012.

CEPED UFSC. Centro Universitário de Estudos e Pesquisa em Engenharia e Defesa Civil. Atlas Brasileiro de Desastres Naturais 1991 a 2010: volume Paraná. Florianópolis: CEPED UFSC, 2012.77p.

CRED. Economic Losses, Poverty \& Disasters - 1998-2017. Centre for Research on the Epidemiology of Disasters, 2018.

EIRD/ONU - Estrategia Internacional para la Reducción de Desastres de las Naciones Unidas. Marco de Acció de Hyogo 2005-2015. Aumento de la resiliencia de las naciones y las comunidades ante los desastres: Introducción al Marco de Acción de Hyogo. Genebra: EIRD, 2005.

FERENTZ, L.M.S.; FONSECA, M.N.; PINHEIRO, E.G. "Gestión de riesgo de desastres y los planes municipales de contingencia: estudio de caso en el municipio de Palmeira/PR", Revista Contribuciones a las Ciencias Sociales, 2018.

FONSECA, M.N.; FERENTZ, L.M.S. Ocorrência de Vendavais no Estado do Paraná: um panorama entre 2013 e 2017. Revista Nacional de Gerenciamento de Cidades, v. 8, n. 57, p. 62-78, 2020.

FONSECA, M. N.; GARCIAS, C.M. Comunicação de risco de inundação: instrumento fundamental da gestão de riscos de desastres. DRd - Desenvolvimento Regional em debate, vol.10, p.1139-1159, 2020

FREITAS, C. M.; SILVA, D. R. X.; SENA, A. R. M. de; SILVA, E. L.; SALES, L. B. F.; CARVALHO, D. M. L. de; MAZOTO, M. L.; BARCELLOS, C.; COSTA, A. M.; OLIVEIRA, M. L. C.; CORVALÁN, C. Desastres naturais e saúde: uma análise da situação do Brasil. Ciência \& Saúde Coletiva, v. 19, n. 9, p. 3645-3656, 2014.

FURTADO, J. R. Gestão de riscos de desastres. Florianópolis: CEPED UFSC, 2012.

GUNTHER, W. R.; CICCOTI, L.; RODRIGUES, A. C. Desastres: Múltiplas Abordagens e Desafios. 1 ed. Rio de Janeiro: Elsevier, 2017.

IULIANO, G. The post 2015 Hyogo Framework for Action: Managing risks to achieve resilience. European Commission, Communication from the European Commission to the European and Social Committee and the Committee of the Regions, p.2, 2014.

KELLETT, J.; CARAVANI, A.; PICHON, F. Financing Disaster Risk Reduction: towards a coherent and comprehensive approach. 2014. Disponível em: <https://www.odi.org/sites/odi.org.uk/files/odi-assets/publicationsopinionfiles/9027.pdf>. Acesso em: 06 dez. 2020. 
LAMOND, J.; ADEKOLA, O.; ADELEKAN, I.; EZE, B.; UJOH, F. Information for adaptation and response to flooding, multi-stakeholder perspectives in Nigeria. Climate, v. 7, n. 4, p. 1-18, 2019.

MARCHEZINI, V.; FERREIRA, A. M.; TEIXEIRA DE LIMA, G. R.; GONÇALVES, D. A. Emergency funding public policy for disaster response in Brazil from 2013 to 2017. Sustentabilidade Em Debate, vol.11, n.2, p.266 - 303, 2020

ONU - Organização das Nações Unidas. Como Construir Cidades Mais Resilientes: Um Guia para Gestores Públicos Locais. Genebra: Nações Unidas, 2012. $102 \mathrm{p}$.

OECD. Handbook on Constructing Composite Indicators. Methodology and User Guide. Paris: OECD Publications, 2008.

PALEARI, S. Natural disasters in Italy: do we invest enough in risk prevention and mitigation? International Journal of Environmental Studies, vol.75, n.4, p.673-687, 2018

PARANÁ. Plano Plurianual 2020-2023: Lei n²0.077, de 18 dezembro de 2019. Curitiba: Governo do Estado do Paraná, 2019.

PARANÁ. Anuário da Defesa Civil do Paraná: Ações Desenvolvidas em 2018. Curitiba: Coordenadoria Estadual de Proteção e Defesa Civil, 2020.

PHAUP, M.; KIRSCHNER, C. Budgeting for disasters: focusing on the good times OECD Journal on Budgeting, vol.1, p. 1-24, 2010

PINHEIRO. E. G. Orientações para o planejamento em Proteção e Defesa Civil: Plano Estadual de Proteção e Defesa Civil. Curitiba: FUNESPAR, 2017.

PINHEIRO, E.G.; FERENTZ, L.M.S.; FONSECA, M.N. As Emergências Ambientais no Paraná e as Intersecções com o Sistema Estadual de Proteção e Defesa Civil. Redes (Santa Cruz do Sul. Online), v. 24, n. 2, p. 81- 98, maio-agosto, 2019.

PORTAL DA TRANSPARÊNCIA. Detalhamento Convênios e Outros Acordos. Controladoria-Geral da União, 2020. Disponível em: <www.portaltransparencia.gov.br/convenios/>. Acesso em: 22 mai. 2020.

RIBEIRO, D.; BOREKI, V. Falta de pessoal prejudica ações da Defesa Civil. Gazeta do Povo, 2010. Disponível em: http://www.gazetadopovo.com.br/vida-e-cidadania/faltade-pessoal-prejudica-acoes-da-defesa-civil-1ad2lvvsfc6t304b71camt366>. Acesso em: 20 fev. 2020.

TCU. Falta de objetividade na classificação dos municípios em risco compromete programa de prevenção a desastres naturais. Tribunal de Contas da União, 2017. Disponível em: <http://portal.tcu.gov.br/imprensa/noticias/falta-de-objetividade-na- 
Estruturação de Indicadores na Priorização de Concessão de Recursos para obras voltadas à Redução de Riscos de Desastres entre os Municípios do Estado do Paraná

classificacao-dos-municipios-em-risco-compromete-programa-de-prevencao-adesastres-naturais.htm>. Acesso em: 22 fev. 2020.

TCU. Recursos para prevenção de desastres naturais são distribuídos sem critérios técnicos. Tribunal de Contas da União, 2020. Disponível em: $<$ https://portal.tcu.gov.br/imprensa/noticias/recursos-para-prevencao-de-desastresnaturais-sao-distribuidos-sem-criterios-tecnicos.htm>. Acesso em: 22 mai. 2020.

UNISDR (United Nations International Strategy for Disaster Reduction). Sendai framework for disaster risk reduction 2015-2030. Geneva: UNISDR, 2015.

VESTENA, L.R. A importância da hidrologia na prevenção e mitigação de desastres naturais. Ambiência - Revista do Setor de Ciências Agrárias e Ambientais: Guarapuava, v.4 n.1, p. 151-162, 2007.

Eduardo Gomes Pinheiro. Doutor e Mestre em Gestão Urbana pela Pontifícia Universidade Católica do Paraná, Bacharel em Segurança Pública - Curso de Formação de Oficiais pela Academia Policial Militar do Guatupê - APMG. Especialista em Emergências Ambientais, em Administração - Segurança Pública, em Metodologia do Ensino Superior e Educação à Distância e em Redução do Risco de Desastre e Desenvolvimento Local Sustentável. Corpo de Bombeiros do Estado do Paraná. Gabinete do Comando.egopinheiro@hotmail.com

Larissa Maria da Silva Ferentz. Doutoranda e Mestra em Gestão Urbana pela Pontifícia Universidade Católica do Paraná, possui especialização em Gestão Ambiental pelo Instituto Souza e graduação em Engenharia Ambiental pela PUCPR. Pontifícia Universidade Católica do Paraná. ferentzengenharia@gmail.com

Murilo Noli da Fonseca. Mestrando em Gestão Urbana pela Pontifícia Universidade Católica do Paraná, possui especialização em Gestão Ambiental pelo Instituto Souza e graduação em Geografia (bacharel) pela Universidade Federal do Paraná. murilonoli@gmail.com

Como citar: PINHEIRO, Eduardo Gomes; FERENTZ, Larissa Maria da Silva; FONSECA, Murilo Noli da. Estruturação de Indicadores na Priorização de Concessão de Recursos para obras voltadas à Redução de Riscos de Desastres entre os Municípios do Estado do Paraná. Redes (St. Cruz Sul, Online), Santa Cruz do Sul, v. 25, p. 2737-2759, 2020. ISSN 1982-6745. doi:https://doi.org/10.17058/redes.v25i0.15287. 


\section{CONTRIBUIÇÃO DE CADA AUTOR}

a. Fundamentação teórico-conceitual e problematização: Eduardo Gomes Pinheiro

b. Pesquisa de dados e análise estatística: Eduardo Gomes Pinheiro e Murilo Noli da Fonseca

c. Elaboração de figuras e tabelas: Eduardo Gomes Pinheiro e Murilo Noli da Fonseca

d. Elaboração e redação do texto: Larissa Maria da Silva Ferentz

e. Seleção das referências bibliográficas: Larissa Maria da Silva Ferentz

Fontes de financiamento: O presente trabalho foi realizado com apoio da Coordenação de Aperfeiçoamento de Pessoal de Nível Superior - Brasil (CAPES) Código de Financiamento 001. 